\title{
Synthesis of Highly Oxygenated Carbocycles by Stereoselective Coupling of Alkynes to 1,3- and 1,4-Dicarbonyl Systems
}

Matthew J. Kier, ${ }^{\dagger}$ Robert M. Leon, ${ }^{\dagger}$ Natasha F. O’Rourke, ${ }^{\dagger}$ Arnold L. Rheingold, ${ }^{\dagger}$ and Glenn C. Micalizio* ${ }^{* \dagger}$

${ }^{\dagger}$ Department of Chemistry, Burke Laboratory, Dartmouth College, Hanover, New Hampshire 03755, United States

${ }^{\ddagger}$ Department of Chemistry, University of California-San Diego, La Jolla, California 92093, United States

Supporting Information

ABSTRACT: Densely substituted and highly oxygenated carbocycles are challenging targets for synthesis. In particular, those possessing numerous contiguous, fully substituted carbon atoms (i.e., tertiary alcohols and quaternary centers) are often not accessible in a direct fashion, necessitating the strategic decoupling of ringformation from the establishment of functionality about the system. Here, we describe an approach to the construction of highly oxygenated mono-, di-, and polycyclic carbocycles from the reaction of disubstituted alkynes with $\beta$ - or $\gamma$-dicarbonyl systems. These processes embrace a variant of metallacycle-mediated annulation chemistry where initial alkyne-carbonyl coupling is followed by a second, now intramolecular, stereoselective $\mathrm{C}-\mathrm{C}$ bond-forming event. In addition to revealing the basic reactivity pattern in intermolecular settings, we demonstrate that this class of reactivity is quite powerful in a fully intramolecular context and, when terminated by a stereoselective oxidation process, can be used to generate polycyclic systems containing a fully substituted and highly oxygenated five-membered ring.

$\mathrm{H}$ ighly oxygenated carbocycles remain challenging targets for efficient chemical synthesis. ${ }^{1}$ While a great variety of ring-forming reactions are available to assemble diverse polycyclic systems, even the most powerful of modern methods are not well equipped to simultaneously establish numerous and/or contiguous fully substituted $\mathrm{sp}^{3}$ centers (quaternary centers and tertiary alcohols) within the newly formed ring. This deficiency in reaction methodology has resulted in strategies to oxygenated carbocycles that typically proceed in two distinct phases, where ring-formation is strategically decoupled from establishing the dense functionality of the system. ${ }^{1 \mathrm{~d}}$ Despite impressive recent momentum in the development of reactions capable of complementing modern ring-forming processes with sequential functionalization chemistry, ${ }^{2}$ carbocyclic systems that contain numerous/contiguous fully substituted $\mathrm{sp}^{3}$ carbons (i.e., 1-3; Figure $\left.1 \mathrm{~A}\right)^{3}$ remain quite difficult to prepare. Here, we describe a mode of reactivity that can be employed for the formation of five- and sixmembered rings, either in isolation or as part of a polycyclic system, that merges the process of ring-formation with the establishment of densely oxygenated molecular architecture (I and II, $n=0$ or 1 ; Figure 1B).
A.

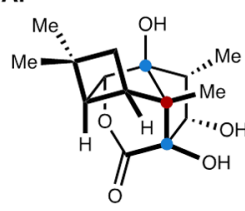

fascicularone I

1

$\bullet$ = tertiary alcohol/ether $\quad$ = quaternary center

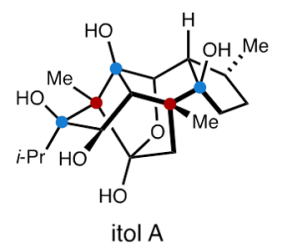

ol $A$

2

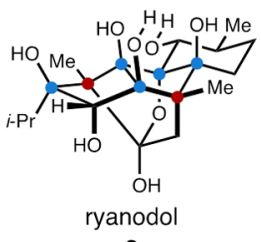

3


(iii)

Figure 1. Introduction.

Study began with the goal of achieving the sequence of bondforming processes summarized in Figure 1C. Chemoselective activation of III through formation of a metallacyclopropene $(i)$ was expected to be followed by carbonyl addition and result in a functionalized oxametallacyclopentene $(i i) .{ }^{4}$ This intermediate was thought to be of potential value in a subsequent $\mathrm{C}-\mathrm{C}$ bond-forming process, where complexation of the distal carbonyl oxygen to the metal center would facilitate a stereocontrolled nucleophilic addition en route to the bridged metal alkoxide-containing system (iii). While such a sequence of bond-forming events has, to our knowledge, never been described for the synthesis of stereodefined diols, ${ }^{5}$ reaction cascades of metallacyclopropane/ene intermediates have been proposed as central characteristics of other Group IV metalmediated annulation reactions. ${ }^{6,7}$ Overall, it was reasoned that the chemical transformations targeted here would accomplish what other annulation reactions in organic chemistry do not,

Received: June 20, 2017

Published: August 27, 2017 
accomplishing five- or six-membered ring-formation while simultaneously establishing at least two tertiary alcohols, with the most complex examples furnishing products that house up to five contiguous fully substituted $\mathrm{sp}^{3}$ carbons.

Our first set of experiments aimed at investigating the feasibility of this reaction design is illustrated in Figure 2. These
(1)



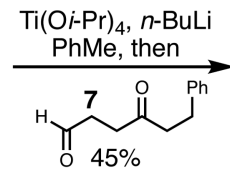

(3)<smiles>CS(C)(C)C#Cc1cccs1</smiles>

(4)<smiles>CC(C)C#CS(C)(=O)=O</smiles>

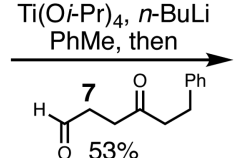

O $53 \%$

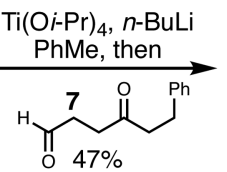<smiles>CS(=O)(=O)C1=C(c2ccccc2)C(O)CC[C@@]1(O)CCc1ccccc1</smiles>

(7)

(6)<smiles>CC#CCCCC(=O)C(C)(C)C(=O)CC</smiles>

16<smiles>CC#CCCCC(=O)C(C)(C)C(=O)C1CC1</smiles>



(8)<smiles>CCC(=O)C(C)(C)C(=O)CCCC#C[18Br]</smiles>

16

(9)

B. Challenging substrates.

<smiles>CC#CCCCC(=O)CCC(C)=O</smiles>

23 unhindered
methyl ketone

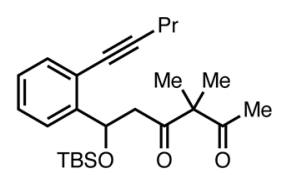

conjugated alkyne

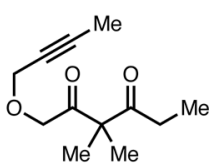

25

Figure 2. Intermolecular alkyne-dicarbonyl coupling reactions.

processes proceeded with modest efficiencies ( $\leq 53 \%$ yield), yet provided the first glimpse of success associated with the basic reaction design. While initial attempts to realize carbocycleformation from the union of TMS-phenylacetylene (4) with methyl 4-oxobutanoate (5) were met with failure (eq 1), it was soon found that replacing the ester of 5 with a ketone led to success. As depicted in eq 2, Ti-mediated coupling of alkyne 4 with the $\gamma$-keto-aldehyde 7 led to formation of the isomerically pure cyclohexene diol 8 in a $45 \%$ isolated yield-notably, no evidence was found for the presence of regio- or stereoisomeric products in this coupling reaction. It is suspected that cyclohexene product $\mathbf{8}$ is formed by initial regioselective alkyne-aldehyde coupling ${ }^{8}$ followed by stereoselective intramolecular reaction of the resulting $\sigma_{\mathrm{C}-\mathrm{Ti}}$ bond of the oxametallacyclopentene with the pendant ketone. As illustrated in eqs 3 and 4 of Figure 2, this annulation process proved to be effective with TMS-alkynes bearing heteroaryl and branched aliphatic substitution (9 and 11). In both cases cyclohexene products were formed that possess a secondary and tertiary allylic alcohol set in a 1,4-syn relationship (10 and 12). ${ }^{9}$ These types of functionalized cyclohexene products are not readily available from other convergent methods for carbocycleformation. $^{10}$

As illustrated in eq 5 of Figure 3, this basic reaction process was effective for coupling an internal alkyne to a 1,3-diketone, although success was only modest (15 was isolated as a single

Figure 3. Annulation reactions involving diketones. Reaction conditions: (a) $\mathrm{Ti}(\mathrm{O} i \text {-Pr })_{4}, i$-PrMgCl, $\mathrm{THF},-78$ to $-20{ }^{\circ} \mathrm{C}$, then aq $\mathrm{NaHCO}_{3}$; (b) $\mathrm{Ti}(\mathrm{O} i \text {-Pr) })_{4}$, i-PrMgCl, THF, -78 to $-20{ }^{\circ} \mathrm{C}$ (or rt), then $t$ - $\mathrm{BuOOH}$, then aq $\mathrm{NaHCO}_{3}$.

isomer in $37 \%$ yield). In this initial reaction with a 1,3-diketone, it was found that changing the nature of the reductant from $n$ $\mathrm{BuLi}$ to $i$-PrMgCl was critical to achieving even this modest level of success. ${ }^{11}$ While it remains unclear why this reaction process was not effective with $n-\mathrm{BuLi}$ as reductant, questions remain regarding the elementary steps of the initial reaction process en route to the relevant Ti-alkyne complex. ${ }^{12}$

Moving forward with the goal of exploring the potential value of this reaction process for delivering densely functionalized polycyclic carbocycles, we shifted to investigating intramolecular variants. Here, chemoselective Ti-mediated alkyne activation in the presence of the dicarbonyl system was reasoned to be an important first step to achieving success. ${ }^{13}$ As illustrated in eqs 6 and 7 of Figure 3A, it was found that stereoselective cyclization of alkyne-containing 1,3-diketones is not only possible, but more efficient than the intermolecular variant. Here, the bicyclo[3.3.0] octane products 17 and 19 were isolated as single isomers in $63 \%$ and $65 \%$ yields, respectively. Next, we considered the penultimate titanium-complexed intermediate in these reactions as a potential valuable species 


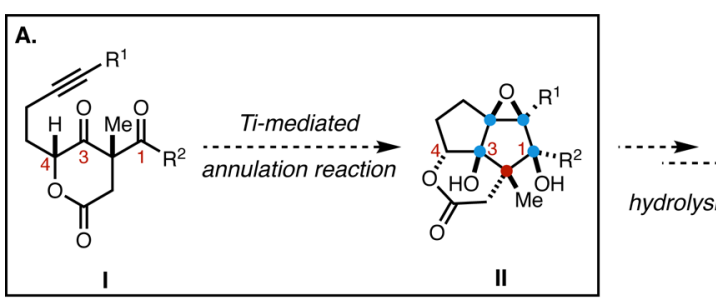

B.
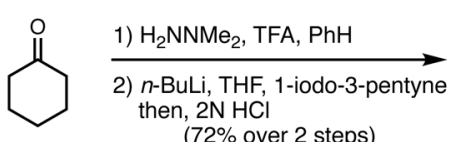

(72\% over 2 steps)

26



27


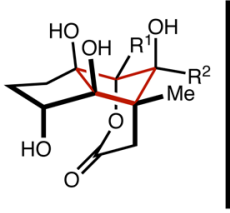

IV


30

Figure 4. Exploring synthesis design with the alkyne-dicarbonyl annulation reaction-control of relative stereochemistry in the ring-forming process, and application to the synthesis of fused tricyclic carbocycles containing a fully substituted cyclopentene or cyclopentane, and including up to six contiguous stereocenters. Reaction conditions: (a) $\mathrm{Ti}(\mathrm{O} i-\mathrm{Pr})_{4}, i-\mathrm{PrMgCl}, \mathrm{THF},-78$ to $-20{ }^{\circ} \mathrm{C}$, then aq $\mathrm{NaHCO}_{3} ;(\mathrm{b}) \mathrm{Ti}(\mathrm{O} i-\mathrm{Pr})_{4}, i-\mathrm{PrMgCl}, \mathrm{THF}$, -78 to $-20{ }^{\circ} \mathrm{C}$, then $t-\mathrm{BuOOH}$, then aq $\mathrm{NaHCO}_{3}$.

for subsequent stereoselective functionalization (i.e., compound iii in Figure 1C). In particular, we recognized that its proximity to the product alkene could facilitate stereoselective oxidation. Pursuit of this concept resulted in the establishment of an annulation procedure that delivers cyclopentene products that possess five consecutive fully substituted $\mathrm{sp}^{3}$ carbons, doing so in a highly stereoselective manner. As illustrated in eq 8 of Figure $3 \mathrm{~A}$, simply terminating the annulation reaction by quenching with $t$ - $\mathrm{BuOOH}^{14}$ results in the stereoselective formation of the epoxydiol-containing bicyclo[3.3.0] octane product 20 in $79 \%$ isolated yield (no evidence was found for the production of stereoisomeric products). ${ }^{15}$

The intramolecular version of this diketone-based annulation reaction was next explored with $\gamma$-diketone substrates to the feasibility of accessing stereodefined and oxygenated hydrindanes. As illustrated in eq 9 of Figure 3A, Ti-mediated annulation, followed by an oxidative quench with $t-\mathrm{BuOOH}$, delivered the highly oxygenated hydrindane 22 in $49 \%$ isolated yield (the structure of $\mathbf{2 2}$ was confirmed by X-ray diffraction).

Not unlike other newly discovered reactions in organic chemistry, this annulation process was found to have limitations (Figure 3B). For example, the diketone 23 delivered a product mixture containing $\sim 30 \%$ of a product derived from monocyclization and intermolecular addition of a propyl group to the unhindered methyl ketone. Alternatively, substrates containing a conjugated alkyne (24) or a propargylic ether (25) were also problematic, perhaps due to varying rates associated with reaction of the intermediate Ti-based organometallic $\left[(i-\mathrm{Pr})_{2} \mathrm{Ti}(\mathrm{O} i-\mathrm{Pr})_{2}\right.$, or decomposition products thereof ${ }^{12}$ with the alkyne vs the dicarbonyl system.

Despite observing some limitations, this alkyne-dicarbonylbased annulation reaction could be valuable in helping to stimulate the invention of new synthesis strategies to complex polyoxygenated targets. To facilitate such adoption of this reactivity in synthesis design, it is important to demonstrate that stereoselectivity of the annulation process can be achieved by substrate control, where pre-existing substrate chirality can be used to control the stereochemical course of the process. In efforts that seek to explore both of these points, focus shifted to considering how the annulation reaction may be wielded to address a complex target-oriented synthesis problem in a unique way.

As illustrated in Figure 4A, a synthesis pathway that embraces the alkyne-dicarbonyl annulation reaction was conceived to be of potential value for accessing the densely functionalized carbocyclic core of ryanodol-a structure that contains a central cyclopentane that is composed of five fully substituted $\mathrm{sp}^{3}$ carbons (four tertiary "alcohols" and one quaternary center). Here, a chiral substrate akin to $\mathbf{I}$ was viewed as a potential precursor to the epoxydiol-containing tricycle II-an intermediate that was postulated to be of value in establishing tricyclic species IV through lactone hydrolysis and ring closure. In the key annulation reaction proposed (I $\rightarrow$ II $)$, stereochemistry would need to be controlled by the $\mathrm{C} 4$ stereocenter, leading to attack at $\mathrm{C} 3$ from the $\alpha$-face and translation of that newly formed stereochemistry to the next $\mathrm{C}-\mathrm{C}$ bond-forming event. After establishing the $\mathrm{C} 1$ tertiary alcohol, the stage would be set for directed epoxidation of the remaining alkene to deliver II.

As illustrated in Figure 4B, the key steps of this annulation were tested with a model system. Cyclohexanone (26) was advanced to the alkynyl ketone 27 by conversion to its corresponding hydrazone, alkylation with 1-iodo-3-pentyne, and hydrolysis. Next, regioselective generation of the kinetic enolate was followed by acylation and stereoselective methylation to deliver substrate 28. To our delight, it was found that exposure of $\mathbf{2 8}$ to the standard conditions for annulation delivered the stereodefined tricyclic product 29 as a single isomer in $40 \%$ isolated yield. Similarly, oxidative quenching of this annulation process with $t$ - $\mathrm{BuOOH}$ delivered the complex epoxydiol 30 in $62 \%$ yield. As we have encountered throughout these investigations, no evidence was found for the production of stereoisomeric products in the intramolecular annulation reactions of $\mathbf{2 8}$.

In conclusion, we report a general annulation strategy for the synthesis of densely functionalized and highly oxygenated carbocycles that proceeds through the union of alkynes with dicarbonyl systems. The reactions that have emerged through 
these studies are complementary to classic carbocycle-forming processes in organic chemistry, delivering products not readily available from Pauson-Khand, Diels-Alder, or Robinson annulation chemistry. The reactivity realized is thought to proceed through a metallacycle-centered reaction cascade that engages each metal-carbon bond of a metallacyclopropene in reactions with two different carbonyl systems. In addition to establishing the basic coupling process and exploring its utility in intramolecular settings, our studies have demonstrated the ability to conduct this annulation reaction in an oxidative manner, delivering carbocyclic products that bear 4-5 contiguous fully substituted $\mathrm{sp}^{3}$ carbons with all $\mathrm{C}-\mathrm{O}$ bonds residing on a single face of the carbocyclic system. Finally, we have demonstrated that relative stereoselection is possible to control with a chiral cyclic substrate, and use of this annulation reaction delivers complex and highly oxygenated tricyclic carbocycles (i.e., 29 and 30) in just a handful of steps from commercially available starting materials (i.e., 26). We look forward to exploring key features of this annulation reaction in ongoing methods development projects and target-oriented synthesis campaigns. ${ }^{16}$

\section{ASSOCIATED CONTENT}

\section{S Supporting Information}

The Supporting Information is available free of charge on the ACS Publications website at DOI: 10.1021/jacs.7b06286.

Experimental procedures and tabulated spectroscopic data for new compounds (PDF)

Crystollagrophic data for compound 22 (CIF)

\section{AUTHOR INFORMATION}

\section{Corresponding Author}

*glenn.c.micalizio@dartmouth.edu

\section{ORCID}

Glenn C. Micalizio: 0000-0002-3408-5570

Notes

The authors declare no competing financial interest.

\section{ACKNOWLEDGMENTS}

We gratefully acknowledge financial support of this work by the National Institutes of Health, NIGMS (GM080266 and GM124004). The authors also thank Skyler Svendsen for performing an early example of the alkyne coupling reaction with a $\gamma$-keto aldehyde.

\section{REFERENCES}

(1) (a) Wender, P. A. Nat. Prod. Rep. 2014, 31, 433-440. (b) Ishihara, Y.; Baran, P. S. Synlett 2010, 2010, 1733-1745. (c) Burns, N. Z.; Baran, P. S.; Hoffmann, R. W. Angew. Chem., Int. Ed. 2009, 48, 2854-2867. (d) Chen, K.; Baran, P. S. Nature 2009, 459, 824-828.

(2) For recent reviews, see: (a) Hartwig, J. F. J. Am. Chem. Soc. 2016, 138, 2-24. (b) Qiu, Y.; Gao, S. Nat. Prod. Rep. 2016, 33, 562-581. (c) Nakamura, A.; Nakada, M. Synthesis 2013, 45, 1421-1451.

(d) Chen, D. Y.-K.; Youn, S. W. Chem. - Eur. J. 2012, 18, 9452-9474. (e) Gutekunst, W. R.; Baran, P. S. Chem. Soc. Rev. 2011, 40, 19761991.

(3) (a) Akasaka, H.; Shione, Y. Helv. Chim. Acta 2005, 88, 29442950. (b) Chai, X.-Y.; Bai, C.-C.; Shi, H.-M.; Xu, Z.-R.; Ren, H.-Y.; Li, F.-F.; Lu, Y.-N.; Song, Y.-L.; Tu, P.-F. Tetrahedron 2008, 64, 57435747. (c) Kelly, R. B.; Whittingham, D. J.; Wiesner, K. Can. J. Chem. 1951, 29, 905-910. (d) Srivastava, S. N.; Przybylska, M. Can. J. Chem. 1968, 46, 795-797. For an impressive synthetic route to ryanodol and ryanodine, see: (e) Chuang, K. V.; Xu, C.; Reisman, S. E. Science 2016, 353, 912-915. (f) Xu, C.; Han, A.; Virgil, S. C.; Reisman, S. E. ACS Cent. Sci. 2017, 3, 278-282.

(4) For an example of a Ti-ethylene complex reacting with an aldehyde, see: (a) Cohen, S. A.; Bercaw, J. E. Organometallics 1985, 4, 1006-1014. For an example of regioselective coupling of a Ti-alkyne complex to an aldehyde, see: (b) Harada, K.; Urabe, H.; Sato, F. Tetrahedron Lett. 1995, 36, 3203-3206.

(5) For a related reaction design that does not deliver stereodefined products, see the following that describe $\mathrm{Nb}$ - and $\mathrm{Ta}$-mediated entries to substituted naphthols: (a) Hartung, J. B.; Pedersen, S. F. J. Am. Chem. Soc. 1989, 111, 5468-5469. (b) Kataoka, Y.; Miyai, J.; Tezuka, M.; Takai, K.; Oshima, K.; Utimoto, K. Tetrahedron Lett. 1990, 31, 369-372.

(6) For a recent review of the Kulinkovich reaction, see: (a) Wolan, A.; Six, Y. Tetrahedron 2010, 66, 15-61. For the titanacycle-tocarbocycle relay reaction, see: (b) Urabe, H.; Narita, M.; Sato, F. Angew. Chem., Int. Ed. 1999, 38, 3516-3518.

(7) For previous uses of $\mathrm{Ti}(\mathrm{O} i-\mathrm{Pr})_{4}$ and $n$-BuLi in metallacyclemediated coupling chemistry, see: (a) Tarselli, M. A.; Micalizio, G. C. Org. Lett. 2009, 11, 4596-4599. (b) Yang, D.; Micalizio, G. C. J. Am. Chem. Soc. 2011, 133, 9216-9219. (c) Chen, M. Z.; Micalizio, G. C. J. Am. Chem. Soc. 2012, 134, 1352-1356. (d) Jeso, V.; Aquino, C.; Cheng, X.; Mizoguchi, H.; Nakashige, M.; Micalizio, G. C. J. Am. Chem. Soc. 2014, 136, 8209-8212. (e) Rassadin, V. A.; Six, Y. Tetrahedron 2014, 70, 787-794. (f) Mizoguchi, H.; Micalizio, G. C. J. Am. Chem. Soc. 2015, 137, 6624-6628. (g) Cheng, X.; Micalizio, G. C. J. Am. Chem. Soc. 2016, 138, 1150-1153. (h) Mizoguchi, H.; Micalizio, G. C. Angew. Chem., Int. Ed. 2016, 55, 13099-13103.

(8) It is known that such Ti-alkyne complexes react in a regioselective manner with aldehydes, where $\mathrm{C}-\mathrm{C}$ bond-formation occurs distal to the TMS group. For additional information, see ref $4 \mathrm{~b}$.

(9) While the isolated yields of products for this cyclohexene-forming annulation hovered around 50\%, the dicarbonyl 7 was completely consumed, and an additional product was routinely identified where the intermediate $\mathrm{Ti}-$ alkyne complex reacted at both carbonyl systems ( 20\%).

(10) syn-1,4-Diols like those present in these products of annulation (eqs 2-4) may be accessible from cycloaddition of the parent cyclohexadiene with ${ }^{1} \mathrm{O}_{2}$, followed by reduction; see: Clennan, E. L.; Pace, A. Tetrahedron 2005, 61, 6665-6691.

(11) All attempts to use more highly substituted alkynes or diketones in this reaction were unsuccessful, and extension of the basic reaction design for the establishment of cycloheptenes was not successful.

(12) See: Eisch, J. J.; Adeosun, A. A.; Gitua, J. N. Eur. J. Org. Chem. 2003, 2003, 4721-4727.

(13) An intramolecular Ti-mediated alkyne-ketone cyclization has been reported: Morlender-Vais, N.; Solodovnikova, N.; Marek, I. Chem. Commun. 2000, 1849-1850.

(14) (a) Katsuki, T.; Sharpless, K. B. J. Am. Chem. Soc. 1980, 102, 5974-5976. For recent examples of employing a metal alkoxide intermediate in directed epoxidation by the addition of $\mathrm{Ti}(\mathrm{O} i-\mathrm{Pr})_{4}$ and t-BuOOH, see: (b) Kelly, A. R.; Lurain, A. E.; Walsh, P. J. J. Am. Chem. Soc. 2005, 127, 14668-14674. (c) Kim, J. G.; Waltz, K. M.; Garcia, I. F.; Kwiatkowski, D.; Walsh, P. J. J. Am. Chem. Soc. 2004, 126, 1258012585 .

(15) The increase in isolated yield observed for product 20, in comparison to 17 , likely reflects the increased stability of the epoxide product (in comparison to the ene-diol) to the chromatographic conditions employed for purification of the crude reaction mixture.

(16) For a recent review on the use of metallacycle-mediated crosscoupling chemistry in natural product total synthesis, see: O'Rourke, N. F.; Kier, M. J.; Micalizio, G. C. Tetrahedron 2016, 72, 7093-7123. 